\title{
PPAR $\gamma$ induces growth inhibition and apoptosis through upregulation of insulin-like growth factor-binding protein-3 in gastric cancer cells
}

\author{
S.Y. Kim ${ }^{1,2}$, M.S. Kim ${ }^{1}$, M.K. Lee ${ }^{1}$, J.S. Kim ${ }^{3}$, H.K. Yi ${ }^{3}$, S.Y. Nam ${ }^{4}$, D.Y. Lee ${ }^{1,2}$ and P.H. Hwang ${ }^{1,2}$ \\ ${ }^{1}$ Department of Pediatrics, Chonbuk National University Hospital, Jeonju, Korea \\ ${ }^{2}$ Biomedical Research Institute, School of Medicine, Chonbuk National University Hospital, Jeonju, Korea \\ ${ }^{3}$ Department of Biochemistry, School of Dentistry, Chonbuk National University, Jeonju, Korea \\ ${ }^{4}$ Department of Alternative Therapy, Jeonju University, Jeonju, Korea
}

\begin{abstract}
Peroxisome proliferator activator receptor-gamma (PPAR $\gamma$ ) is a ligand-activated transcriptional factor involved in the carcinogenesis of various cancers. Insulin-like growth factor-binding protein-3 (IGFBP-3) is a tumor suppressor gene that has anti-apoptotic activity. The purpose of this study was to investigate the anticancer mechanism of PPAR $\gamma$ with respect to IGFBP-3. PPAR $\gamma$ was overexpressed in SNU-668 gastric cancer cells using an adenovirus gene transfer system. The cells in which PPAR $\gamma$ was overexpressed exhibited growth inhibition, induction of apoptosis, and a significant increase in IGFBP-3 expression. We investigated the underlying molecular mechanisms of PPAR $\gamma$ in SNU-668 cells using an IGFBP-3 promoter/ luciferase reporter system. Luciferase activity was increased up to 15-fold in PPAR $\gamma$ transfected cells, suggesting that PPAR $\gamma$ may directly interact with IGFBP-3 promoter to induce its expression. Deletion analysis of the IGFBP-3 promoter showed that luciferase activity was markedly reduced in cells without putative p53-binding sites $(-\Delta 1755,-\Delta 1795)$. This suggests that the critical PPAR $\gamma$-response region is located within the p53-binding region of the IGFBP-3 promoter. We further demonstrated an increase in PPAR $\gamma$-induced luciferase activity even in cells treated with siRNA to silence p53 expression. Taken together, these data suggest that PPAR $\gamma$ exhibits its anticancer effect by increasing IGFBP-3 expression, and that IGFBP-3 is a significant tumor suppressor.
\end{abstract}

Key words: PPAR $;$; IGFBP-3; Apoptosis; Gastric cancer

\section{Introduction}

Peroxisome proliferator-activated receptors (PPARs) are multifunctional nuclear hormone receptors that influence cell growth, cell differentiation, and cell death (1). There are three PPAR isoforms, PPAR $\alpha$, PPAR $\beta / \delta$, and PPAR $\gamma$, and of these, PPAR $\gamma$ is mainly expressed in adipose tissues. It regulates lipid and glucose metabolism and adipocyte differentiation (2). Because of its role in metabolic regulation, PPAR $\gamma$ has become a molecule of interest in many research areas, serving as a putative therapeutic target in diseases such as type 2 diabetes mellitus, dyslipidemia, inflammatory diseases, and hypertension (3).

While PPAR $\gamma$ was initially regarded solely as a regulator of adipocyte differentiation and glucose homeostasis, it later became evident that it is also involved in cell differentiation, apoptosis and angiogenesis; biological processes that are deregulated in cancer. It is now established that PPAR $\gamma$ ligands, such as rosiglitazone, can inhibit the growth of tumor cells and produce antineoplastic effects in various cancers, including lung, breast, and colon cancer $(4,5)$. One mechanism by which PPAR $\gamma$ exerts its effects is by increasing the expression of proteins involved in apoptosis and regulation of cell growth, such as Bax (BCL2-associated $\mathrm{X}$ ), Bid (BH3 interacting-domain), tumor suppressor p53 (6), and the cyclin-dependent kinase inhibitor (CDKI) p21 (7). PPAR $\gamma$ ligands have been shown to suppress angiogenesis by inhibiting vascular endothelial growth factor (VEGF)receptor 2 expression and blocking VEGF-receptor signaling (8). PPAR $\gamma$ agonists such as troglitazone and ciglitazone also inhibit metastasis by inhibiting migration of vascular endothelial cells (9).

Since insulin-like growth factor binding protein-3 (IGFBP-3) also inhibits cancer cell growth independent

Correspondence: Pyoung-Han Hwang: <hwaph@jbnu.ac.kr>. 
of the IGF signaling system, it is now considered a tumor suppressor factor $(10,11)$. The exact anticancer mechanism(s) of IGFBP-3 is not well understood; however, it has been reported that a number of factors, such as transforming growth factor (TGF)- $\beta$, retinoic acid, vitamin $D$, tumor necrosis factor (TNF), and p53, stimulate the expression and secretion of IGFBP-3, thus inhibiting cancer cell growth (12-14). This study presents evidence that a mechanism whereby PPAR $\gamma$ exerts its anticancer effect is by increasing expression of the tumor suppressor gene IGFBP-3.

\section{Material and Methods}

\section{Material}

Cell culture reagents were purchased from Gibco-BRL Technologies (USA). Anti-PPAR $\gamma$, IGFBP-3, p53, and secondary antibodies were purchased from Santa Cruz Biotechnology (USA). Poly(ADP-ribose) polymerase (PARP) antibody was purchased from Cell Signaling Technology (USA).

\section{Cell line and cell culture}

An established human gastric adenocarcinoma cell line (SNU-668), derived from the gastric cancer cells of a Korean patient, was purchased from the Korea Cell Line Bank (Korea). The cells were maintained in RPMI 1640 medium supplemented with $10 \%$ heat-inactivated fetal bovine serum (FBS), $300 \mu \mathrm{g} / \mathrm{mL}$ L-glutamine, $100 \mathrm{U} / \mathrm{mL}$ penicillin $\mathrm{G}$ and $100 \mu \mathrm{g} / \mathrm{mL}$ streptomycin sulfate. Cell cultures were incubated at $37^{\circ} \mathrm{C}$ in a $5 \% \mathrm{CO}_{2}$ atmosphere. Cells from mid-log phase cultures were harvested, washed twice, and resuspended in culture medium prior to use. Cells that had been infected with adenovirus-expressing PPAR $\gamma$ (Ad/PPAR $\gamma$ ), $\mathrm{Ad} / \mathrm{LacZ}$, or empty vector at a multiplicity of infection (MOI) of 50 or 100 were plated in $10 \%$ FBS-RPMI at a density of $2 \times 10^{4}$ cells/well. After the indicated period of culture, trypan blue exclusion was used to assess cell viability by light microscopy. Cell viability was calculated by dividing the number of unstained viable cells count by the total number of cells.

\section{RNA extraction and RT-PCR}

Cells were treated with TRI reagent (Molecular Research Center, USA) and total RNA was extracted according to the manufacturer's instructions. RT-PCR and agarose gel electrophoresis were performed as previously described (15). Specific primer sets were designed from published cDNA sequences: sense PPAR $\gamma$ : 5'-TAA AGA GCC TGC GAA AGC-3' and antisense PPAR $\gamma$ : 5'-TTG GCA GTG GCT CAG GAC-3'; sense actin: 5'-TGA CGG GGT CAC CCA CAC TGT GCC CAT CTA-3' and antisense actin: 5'-CTA GAA GCA TTT GCG GTG GAC GAT GGA GGG-3'.

\section{Preparation and administration of the recombinant adenoviral vector}

The E1/E3-deleted replication-deficient recombinant adenovirus was made using the AdEasy system (Quantum
Biotechnologies, Canada) as previously described (15). In brief, Kpn-Xhol restriction fragments from pcDNA3/PPARr and pcDNA3/p53 were ligated into Kpn-Xhol-digested pShuttle cytomegalovirus (CMV). Recombination into the pAdEasy viral backbone was accomplished in bacteria (recombination deficient Escherichia coli, strain BJ5183) according to the manufacturer's instructions. Recombinant adenoviruses were amplified in QBI-293A cells. Following amplification, lysates containing clonal recombinant adenovirus were purified by $\mathrm{CsCl}$ gradient centrifugation $\left(100,000 \mathrm{~g}\right.$ at $4^{\circ} \mathrm{C}$ for $\left.20 \mathrm{~h}\right)$. Suspensions of recovered virus were aliquoted and stored at $-20^{\circ} \mathrm{C}$ in $5 \mathrm{mM}$ Tris buffer containing $50 \mathrm{mM} \mathrm{NaCl}, 0.05 \%$ bovine serum albumin, and $25 \%$ glycerol. Virus was titrated by serial dilution infection of QBI-293A cells, and plaques were counted under an overlay of $0.3 \%$ agarose, $10 \%$ fetal bovine serum, and $1 \%$ DMEM. For adenovirus infection, subconfluent cells were infected with adenovirus at a known $\mathrm{MOI}$ in culture medium supplemented with $2 \%$ FBS. After gentle and frequent shaking for $1 \mathrm{~h}$ at $37^{\circ} \mathrm{C}$, cells were washed twice with phosphatebuffered saline (PBS) and fresh complete medium was added.

\section{Luciferase assay}

A 1.87-kb human IGFBP-3 promoter-luciferase reporter construct pGL3 (-1936/-64) and a series of deletion constructs including pGL3- $\Delta 1100$, pGL3- $\Delta 1600$, pGL3- $\Delta 1755$ and pGL3- $\Delta 1795$ were generated as previously described (16). To generate pGL3-IGFBP-3, IGFBP-3 was digested with Bgl II, and the IGFBP-3 promoter fragment was cloned into $\mathrm{Bgl}$ II site of the pzGL-3 basic vector (Promega, USA). To generate pGL3- $\Delta 1100$, IGFBP-3 was double digested with Ssp I and Bgl II and the $-1936 /-64$ region of the IGFBP3 promoter was recombined into the pzGL-3 basic vector. SNU-668 cells were transfected for $24 \mathrm{~h}$ with IGFBP-3 promoter/pGL3 constructs using lipofectamine (Invitrogen, USA). The cells were washed with PBS, followed by infection with Ad/PPAR $\gamma$ in serum-free medium for $4 \mathrm{~h}$. After $48 \mathrm{~h}$, cell lysates were prepared and luciferase activity was measured using the Dual Luciferase kit (Promega) according to the manufacturer's instructions.

\section{p53 siRNA transfection}

p53 (sc-29435) siRNA was purchased from Santa Cruz Biotechnology. SNU-668 cells were transferred to 6-well plates $\left(2 \times 10^{5} /\right.$ well), and allowed to grow overnight. p53 siRNA (200 pmol) and lipofectamine $(5 \mu \mathrm{L})$ were diluted into OPTI-MEM (Invitrogen) to a total volume of $250 \mu \mathrm{L}$. After incubation at ambient temperature for 20 min and washing with serum-free RPMI medium, the siRNA/lipofectamine mix was added to the cells. Following incubation at $37^{\circ} \mathrm{C}$ for $6 \mathrm{~h}$, the siRNA/lipofectamine mix was replaced with complete culture medium.

\section{Crystal violet assay}

Cells were transferred to 6 -well plates $\left(1 \times 10^{5}\right)$ and infected with adenovirus vector as described above. After 3 
days, cells were fixed, stained with $0.5 \%$ crystal violet, rinsed 3 times with deionized water, and allowed to air-dry.

\section{Western blot analysis}

Western blots were performed as previously described (15). In brief, cells were harvested 2-3 days after adenovirus infection. Proteins were extracted from transfected SNU668 cells using lysis buffer and quantified by the Bradford dye-binding procedure (Bio-Rad, USA). Aliquots containing $20 \mu \mathrm{g}$ protein were separated by $8 \%$ sodium dodecyl sulfate-polyacrylamide gel electrophoresis (SDS-PAGE) under denaturing conditions and transferred to Hybond-P membranes (Amersham, USA). After blocking with 5\% skim milk in Tris-buffered saline and Tween 20 (TTBS), the membranes were incubated with primary antibody for $2 \mathrm{~h}$. Protein signals were detected by enhanced chemiluminescence (NEN, USA).

\section{Statistical analyses}

Results are reported as means $\pm S D$. $P<0.05$ was considered to be statistically significant. Statistical significance between groups was assessed by the unpaired Student's t-test.

\section{Results}

Inhibition of cell growth and induction of apoptosis in SNU-668 cells by PPAR $\gamma$

The anticancer effect of PPAR $\gamma$ was evaluated in SNU-668 cells infected with Ad/PPAR $\gamma$ (50 MOI). Robust expression of PPAR $\gamma$ was observed after 2 days (Figure $1 \mathrm{~A}$ ) and was coincident with marked inhibition of cell growth and reduction of cell numbers compared with the initial numbers (Figure 1B). The effect on cell growth was readily apparent 2 days after transfection, and even more prominent on days 3 and 4.

We also assayed the levels of PARP protein, a caspase3 substrate and key apoptosis-linked protease that is important in maintaining cell viability and DNA repair in response to environmental stress. Cleavage of PARP facilitates cellular disassembly and serves as a marker for cells undergoing apoptosis. We monitored enzyme activity
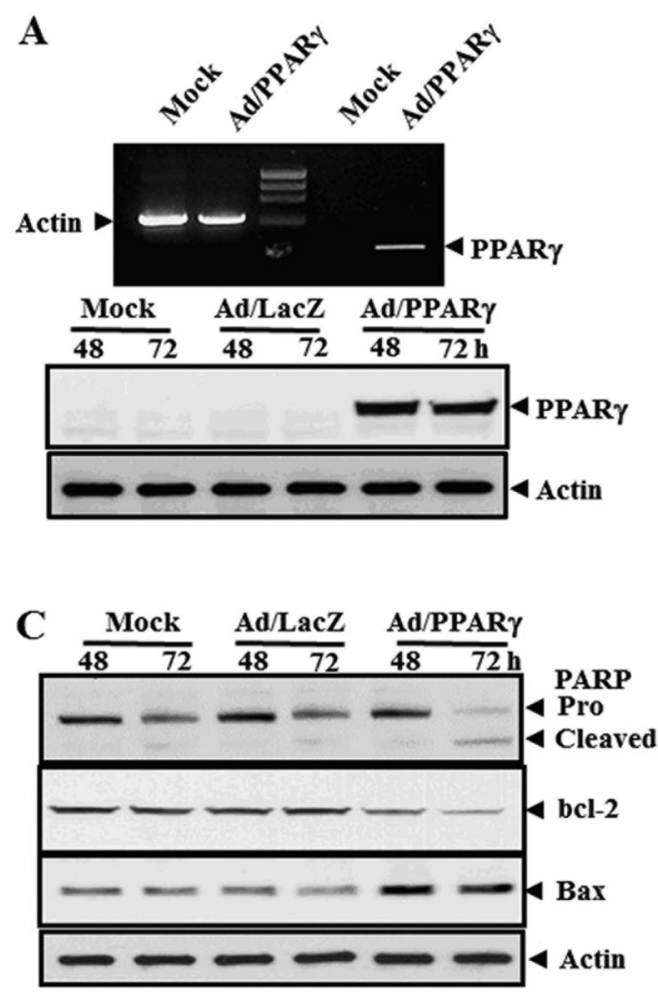
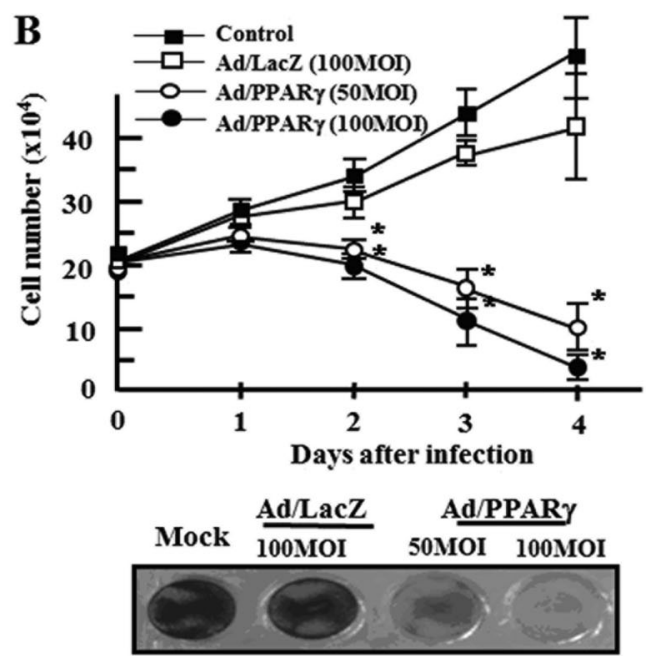

Figure 1. Effect of peroxisome proliferator activator receptor-gamma (PPAR $\gamma$ ) overexpression on cell growth and apoptosis. A, Analysis of PPAR $\gamma$ expression (upper panel, RT-PCR) and PPAR $\gamma$ protein (lower panel, Western blot) in SNU-668 cells infected with adenovirusexpressing (Ad)/PPAR $\gamma$. B, Inhibition of cell growth in SNU-668 cells infected with Ad/PPAR $\gamma$. Upper panel, Cells were infected with Ad/PPAR $\gamma$ or $\mathrm{Ad} / \mathrm{LacZ}$ at the indicated $\mathrm{MOI}$ for $4 \mathrm{~h}$ and then allowed to grow under standard culture conditions for a further 4 days. Cell number was determined by direct counting after trypan blue staining. Data are reported as means $\pm S D$ of 3 independent experiments. ${ }^{*} P<0.05$ compared to control cells (Student's $t$-test). Lower panel, Crystal violet assay. Cell growth in mock-treated and Ad/LacZ-treated cells compared to cells treated with Ad/PPAR $\gamma$. C, Effect of PPAR $\gamma$ overexpression on PARP, Bcl-2 and Bax in SNU-668 cells infected with Ad/PPAR $\gamma$. Cell lysates were collected and processed at 48 and $72 \mathrm{~h}$ after infection, and total protein was analyzed by Western ligand blot with specific antibody. 

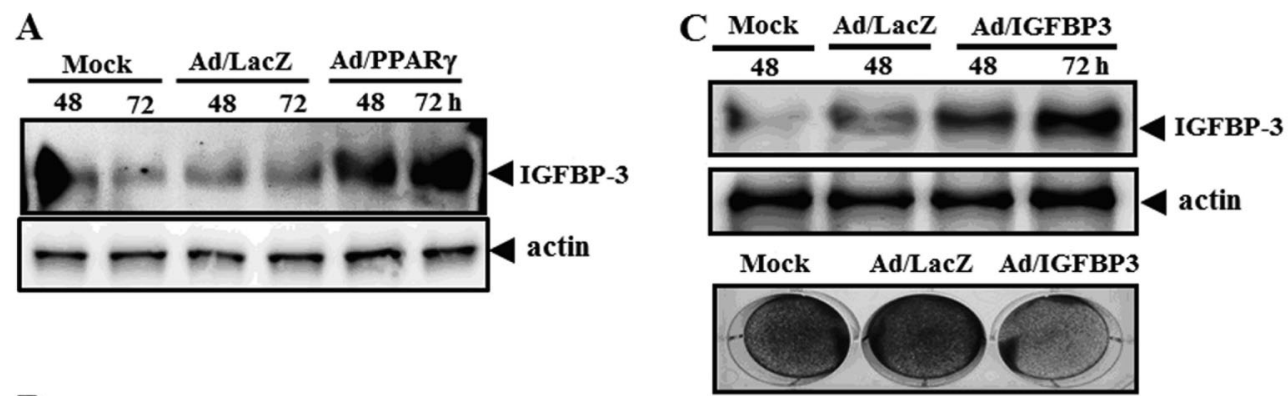

B

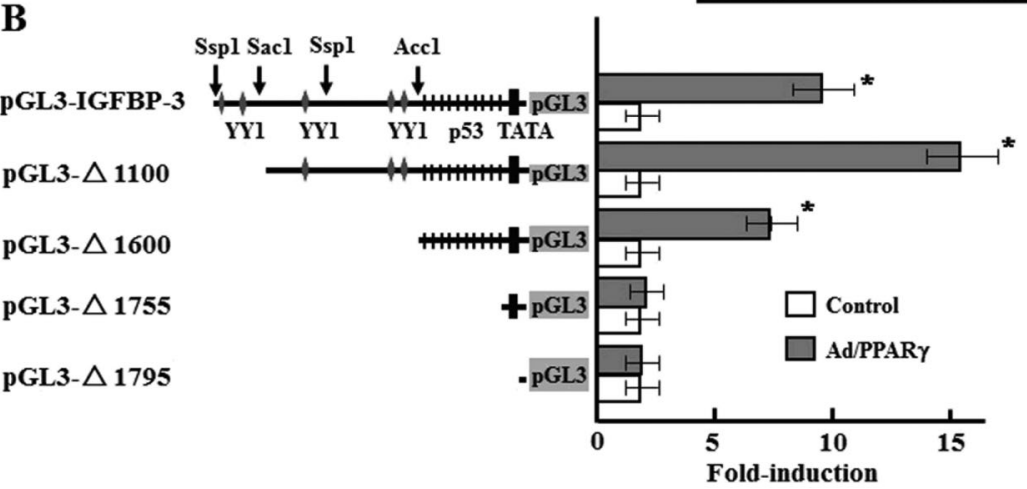

Figure 2. Effect of peroxisome proliferator activator receptor-gamma (PPAR $\gamma$ ) on insulin-like growth factor-binding protein-3 (IGFBP-3) expression and IGFBP-3 promoter activity. A, Western blot analysis of IGFBP-3 protein in SNU-668 cells infected with adenovirusexpressing (Ad)/PPAR $\gamma$. B, Analysis of PPAR $\gamma$-induced IGFBP-3 promoter activation. SNU-668 cells were transiently transfected with a luciferase reporter vector containing the full-length 1.9-kb IGFBP-3 promoter fragment or deletion variants of the IGFBP-3 promoter. After $24 \mathrm{~h}$, cells were treated with Ad/PPAR $\gamma$ in serum-free media for $4 \mathrm{~h}$. Luciferase activity was measured in cell lysates $48 \mathrm{~h}$ after Ad/PPAR $\gamma$ infection. Data are reported as the means of fold-increase in luciferase activity of Ad/PPAR $\gamma$ transfected cells relative to control cells not receiving Ad/PPAR $\gamma$. ${ }^{*} \mathrm{P}<0.05$ compared to the Ad/LacZ-infected cells (Student's $t$-test). C, Effect of IGFBP-3 overexpression, induced by Ad/IGFBP-3 infection, on the growth of SNU-668 cells. Upper panel, Western blot showing IGFBP-3 protein levels in mock-treated cells, Ad/LacZ-treated cells and cells treated with Ad/IGFBP-3. Lower panel, Crystal violet assay. Cell growth in mock-treated and Ad/LacZ-treated cells compared to cells treated with Ad/IGFBP-3.

using an antibody that binds to the $89-\mathrm{kDa}$ fragment of the active enzyme. The active enzyme was present in Ad/PPAR $\gamma$-transduced cells, but not in mock-transduced control or Ad/LacZ-transduced cells, indicating that PPAR $\gamma$ over-expression provides a stimulus for induction of apoptosis, and that the marked inhibitory effect on tumor cell growth by PPAR $\gamma$ is related to its ability to induce apoptosis. We also examined the effect of PPAR $\gamma$ on the expression of the anti-apoptotic protein $\mathrm{Bcl}-2$, and the pro-apoptotic protein Bax, during induction of apoptosis in Ad/PPAR $\gamma$ transduced cells. Western blot analysis showed decreased $\mathrm{Bcl}-2$ protein and increased Bax protein expression in Ad/PPAR $\gamma$-transduced cells compared with control cells (Figure 1C).

\section{Relationship between IGFBP-3 expression and inhibition of cell growth by PPAR $\gamma$}

It has been shown that IGFBP-3 can inhibit cancer cell growth through pathways independent of the IGF signaling system $(10,11)$. In addition to inhibiting cell growth and inducing apoptosis (Figure 2A and B), infection of SNU-668 cells with Ad/PPAR $\gamma$ induced a large increase in IGFBP-3 expression (Figure 2A), suggesting a relationship between IGFBP-3 expression and inhibition of cell growth by PPAR $\gamma$.

To investigate the molecular mechanisms underlying the effect of PPAR $\gamma$ on IGFBP-3 expression, we examined whether PPAR $\gamma$ directly affects transcription from the IGFBP-3 gene promoter. SNU-668 cells were transiently transfected with pGL3-IGFBP-3, a luciferase expression vector containing the full human IGFBP-3 pGL3 promoter construct (-1936/-64), promoter deletion constructs (pGL3$\Delta 1100$, pGL3- $\Delta 1600$, pGL3- $\Delta 1755$ and pGL3- $\Delta 1795)$, or the pGL3 vector alone before infection with Ad/PPAR $\gamma$. Luciferase activity was robust in cells transfected with the full promoter sequence and even greater in cells transfected with the pGL3- $\Delta 1100$ deletion construct, which lacks 800 bp from the $5^{\prime}$ end of the full promoter sequence. In contrast, luciferase activity was minimal to absent in cells receiving the vector control (Figure 2B). These observations suggest that PPAR $\gamma$ induced the expression of IGFBP-3 through direct interaction with elements in the IGFBP-3 promoter.

Notably, cells transfected with the pGL3- $\Delta 1600$ construct exhibited robust luciferase activity compared to control cells (Figure 2B), but luciferase activity was absent in cells 
expressing the pGL3- $\Delta 1755$ or pGL3- $\Delta 1795$ constructs. The region deleted in pGL3- $\Delta 1755$ and pGL3- $\Delta 1795$ contains p53-binding sites. Thus, the critical PPAR $\gamma$-responsive elements are located in the region containing p53-binding sites in the IGFBP-3 promoter.

We also evaluated whether IGFBP-3 itself exerts a direct effect on inhibition of SNU-668 cell growth. When the IGFBP-3 gene was overexpressed in SNU-668 cells using adenovirus (Ad/IGFBP-3), more significant cell growth retardation was observed in Ad/IGFBP-3 transduced SNU668 cells than in control and Ad/LacZ-transduced cells (Figure 2C).

Induction of IGFBP-3 expression by PPAR $\gamma$ in cells in which p53 expression was inhibited

Having observed that sequences containing the p53binding sites in the promoter region of IGFPB-3 were required for IGFBP-3 promoter activation by PPAR $\gamma$, we next employed siRNA-mediated silencing of p53 to test whether the increased luciferase activity induced by PPAR $\gamma$ was dependent on p53 expression. SNU-668 cells were treated with p53 siRNA before induction of IGFBP-3 expression (by transient transfection) and PPAR $\gamma$ expression (by adenovirus infection). As anticipated, p53 siRNA reduced p53 expression in SNU-668 cells (Figure 3A). Furthermore, IGFBP-3 expression was strongly inhibited in cells lacking full p53 expression (Figure 3A). SNU-668 cells treated with p53 siRNA were transiently transfected for $24 \mathrm{~h}$ with the pGL3-1100 promoter-luciferase reporter plasmid, followed by infection with Ad/PPAR $\gamma$ in serum-free media for $4 \mathrm{~h}$. Luciferase activity was compared in cells with or without p53 siRNA treatment. PPAR $\gamma$-induced luciferase activity was increased over controls even in the absence of p53 siRNA treatment (Figure 3B).
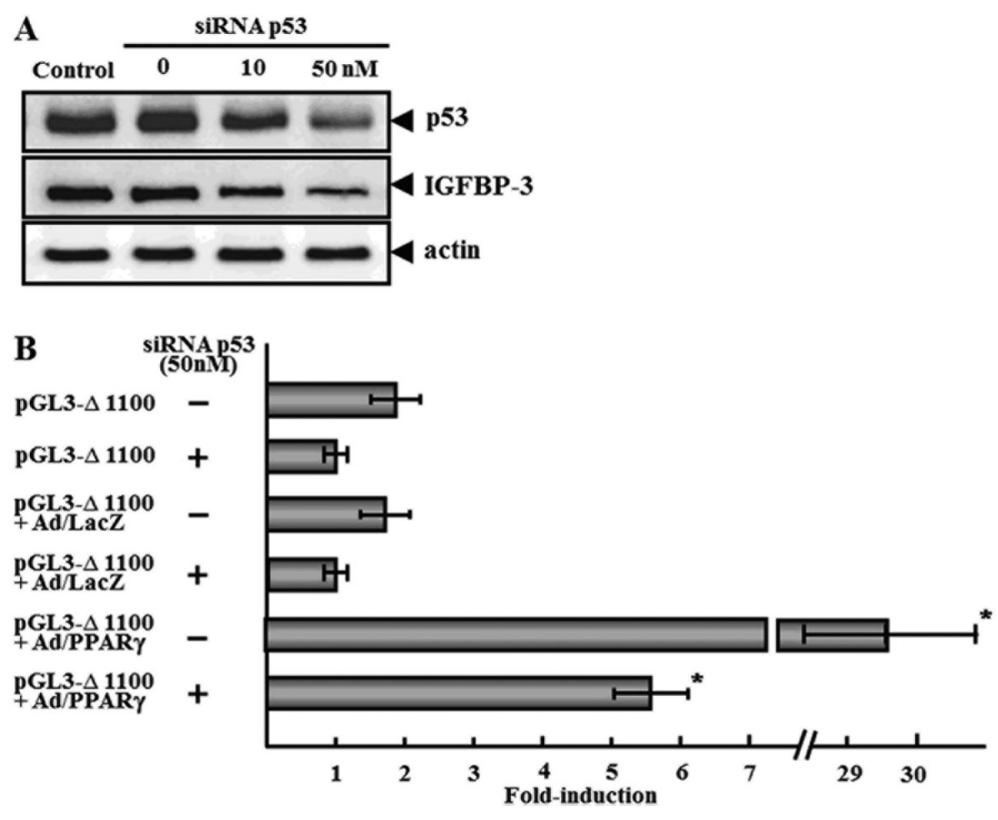

$\mathbf{A}$
Inhibition of cell growth and IGFBP-3 expression by rosiglitazone, a PPAR $\gamma$ agonist

At concentrations of $1-10 \mu \mathrm{M}$, rosiglitazone, a known PPAR $\gamma$ agonist (4), induced growth inhibition of PPAR $\gamma$ transfected SNU-668 cells (Figure 4A). The maximal effect was observed at a concentration of $5 \mu \mathrm{M}$. In PPAR $\gamma-$ transfected SNU-668 cells, treatment with $5 \mu \mathrm{M}$ rosiglitazone increased luciferase activity 4 -fold over untreated cells (Figure 4B), reflecting the known antineoplastic effects of the agonist. To verify the increased luciferase activity of the IGFBP-3 promoter in PPAR $\gamma$-transfected SNU-668 cells following rosiglitazone treatment, we analyzed the expression of IGFBP-3 after rosiglitazone treatment. Rosiglitazone increased IGFBP-3 expression in PPAR $\gamma$-transfected SNU668 cells, which was well correlated with luciferase activity (Figure 4C).

\section{Discussion}

The survival rate of patients with gastric cancer has increased dramatically since early detection and wide-range radical resection have been available. Nevertheless, gastric cancer is still a malignancy with high patient mortality. PPAR $\gamma$ plays an important role in controlling cellular metabolism (17), and it also plays a role in inhibition of cell growth and induction of apoptosis in various types of cancer cells. Because of this, numerous studies have evaluated the therapeutic value of PPAR $\gamma$ in cancer. A common strategy for investigating novel approaches to treatment of gastric cancer has been to focus on interactions among the multiple factors known to be related to cancer progression (i.e., growth factors, oncogenes, tumor suppressor genes, and cell adhesion molecules) (18). However, the interactions of PPAR $\gamma$ with other antitumor factors and their precise
Figure 3. Effect of p53 siRNA on insulin-like growth factor-binding protein-3 (IGFBP-3) expression and IGFBP-3 promoter activity. $A$, Western blot analysis of p53 and IGFBP-3 protein. The anti-actin blot indicates equal protein loading in each lane. $B$, Analysis of IGFBP-3 promoter activation by PPAR $\gamma$. SNU-668 cells were treated with p53 siRNA for $6 \mathrm{~h}$. The cells were then transiently transfected $(24 \mathrm{~h})$ with the pGL3-1100 promoter-luciferase reporter plasmid, followed by infection with adenovirus-expressing (Ad)/PPAR $\gamma$ in serum-free media. Controls were cells not treated with $p 53$ siRNA and cells treated with $\mathrm{Ad} / \mathrm{LacZ}$. Data are reported as means $\pm \mathrm{SD}$ of 3 independent experiments. ${ }^{*} \mathrm{P}<0.05$ compared to Ad/LacZ-infected cells without p53 siRNA (Student's $t$-test). 
mechanisms, especially in gastric cancer, have not been thoroughly defined.

The expression of PPAR $\gamma$ in gastric cancer tissue was reported to be markedly reduced compared to its expression in normal tissue (19), and recent studies have indicated that apoptosis is induced following the administration of PPAR $\gamma$ ligands such as ciglitazone or 15-deoxy-12, 14-prostaglandin J2 (15dPGJ2) in the colorectal carcinoma cell lines HT-29 and Colo-205 (20), and in MCG-803 human gastric cancer cells (21). Other recent studies have demonstrated that isorhamnetin, a 3'-O-methylated metabolite of quercetin (22) and cannabinoids (23), can mediate antitumor effects through modulation of the PPAR $\gamma$ activation pathway in gastric cancer and hepatocellular carcinoma. Therefore, we evaluated the effect of Ad/PPAR $\gamma$ infection in SNU-668 cells, a gastric adenocarcinoma cell line in which PPAR $\gamma$ is not normally expressed. PPAR $\gamma$ expression induced inhibition of cell growth and apoptosis in
SNU-668 cells (Figure 1), strengthening the evidence that PPAR $\gamma$ inhibits tumor growth in gastric cancer cells via induction of apoptosis. Other studies have reported that PPAR $\gamma$ ligands such as 15dPGJ2 can induce apoptosis in MCG-803 gastric cancer cells (21), and this study shows that PPAR $\gamma$ expression, established in SNU-668 cells by $\mathrm{Ad} /$ PPAR $\gamma$ infection, can directly induce growth inhibition and apoptosis.

Because of its function as an antitumor agent independent of the IGF signaling pathway, IGFBP-3 is now recognized as a tumor suppressor factor $(10,11)$. The antitumor activity of IGFBP-3 is related to its level of expression, and factors such as retinoic acid, TNF, p53 and butyric acid mediate IGFBP-3 expression through direct induction of its transcription (24). This study demonstrates that the response region of PPAR $\gamma$ exists within the promoter region of the IGFBP-3 gene and thus indicates that PPAR $\gamma$ can directly increase the expression of IGFBP-3 (Figure 2). We
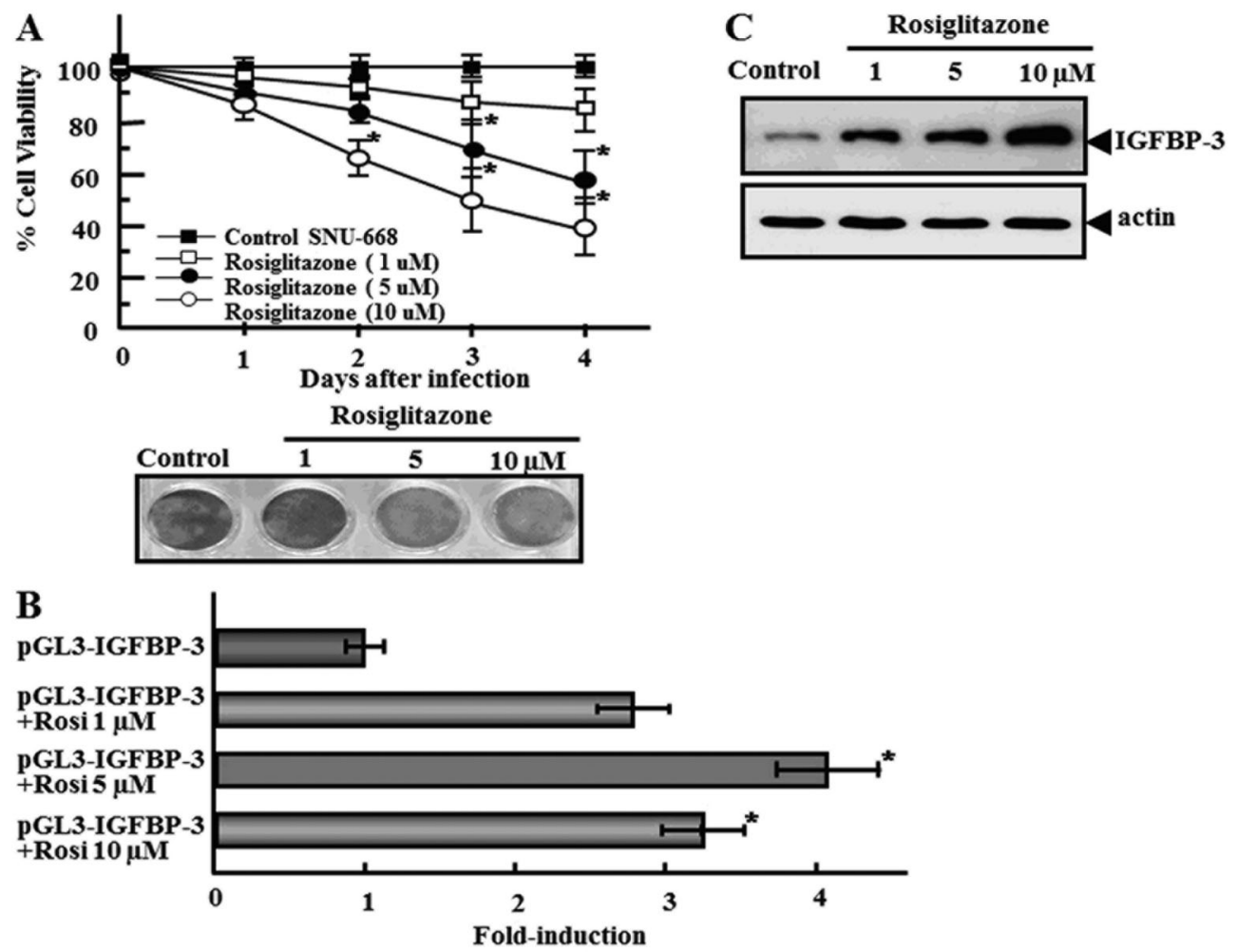

Figure 4. Effect of the peroxisome proliferator activator receptor-gamma (PPAR $\gamma$ ) agonist rosiglitazone (Rosi) on cell viability, IGFBP-3 promoter activity, IGFBP-3 expression. A, The effect of rosiglitazone on the viability of PPAR $\gamma$ transfected SNU-668 cells. Upper panel, PPAR $\gamma$ transfected cells were treated with various concentrations $(1-10 \mu \mathrm{M})$ rosiglitazone and then allowed to grow under standard culture conditions for a further 4 days. The number of viable cells was determined by direct counting after trypan blue staining, and data are reported as the percent of the cell number before treatment. Lower panel, An equal number of cells were treated with increasing concentrations $(1-10 \mu \mathrm{M})$ of rosiglitazone and incubated for $72 \mathrm{~h}$. Cell viability was assessed using the crystal violet assay. $B$, Analysis of IGFBP-3 promoter activation by rosiglitazone. SNU-668 cells were transiently transfected with a luciferase reporter plasmid containing the full length IGFBP-3 promoter (pGL3-IGFBP-3), then infected with adenovirus-expressing (Ad)/PPAR $\gamma$ for $4 \mathrm{~h}$. Twentyfour hours post transfection, luciferase activity was measured following treatment for an additional $24 \mathrm{~h}$ with rosiglitazone. $C$, Western blot analysis of GFBP-3 protein after rosiglitazone treatment in PPAR $\gamma$ transfected SNU-668 cells. The anti-actin blot indicates equal protein loading in each lane. Data are reported as means $\pm S D$ of 3 independent experiments. ${ }^{*} \mathrm{P}<0.05$ compared to the absence of rosiglitazone treatment (Student's $t$-test). 
also observed inhibition of cell growth (Figure 4A) and increased activity from the IGFBP-3 promoter (Figure 4B) following administration of the PPAR $\gamma$ agonist rosiglitazone in PPAR $\gamma$ transfected SNU-668 cells. Although the DNA consensus sequence TGACCT (25), required for PPARs binding in promoter regions, does not exist within the IGFBP-3 promoter, imperfect motifs, e.g. TGACCn, exist at $-190,-260,-270$ bases upstream from the TATA box. Our data suggest that the imperfect TGACCn motifs are involved in the transcriptional activation of IGFBP-3 by PPAR $\gamma$. The IGFBP-3 promoter contains a cluster of eleven p53 consensus binding sites (14), and the imperfect PPAR $\gamma$ binding motifs (TGACCn) are coincident with part of this cluster. Our analysis of five sequential deletion mutants of the IGFBP-3 promoter indicates a significant loss of IGFBP3 promoter activity in cells transfected with deletion constructs lacking putative p53-binding sites (i.e., pGL3$\Delta 1755$, pGL3- $\Delta 1795$; Figure 2B).

When activated, p53 stimulates the expression of a broad range of genes, including IGFBP-3 (24). A recent study suggests that PPAR $\gamma$ agonists promote growth arrest and apoptosis in breast cancer cells, at least in part through cross-talk between p53 and PPAR $\gamma$ (26). To determine whether p53 is required for the transcriptional activation of IGFBP-3 by PPAR $\gamma$, we examined PPAR $\gamma$-induced luciferase activity in pGL3- $\Delta 1100$-transfected cells pretreated with siRNA (Figure 3B). The PPAR $\gamma$-induced luciferase activity

\section{References}

1. Robinson-Rechavi M, Carpentier AS, Duffraisse M, Laudet V. How many nuclear hormone receptors are there in the human genome? Trends Genet 2001; 17: 554-556, doi: 10.1016/ S0168-9525(01)02417-9.

2. Schoonjans K, Staels B, Auwerx J. The peroxisome proliferator activated receptors (PPARS) and their effects on lipid metabolism and adipocyte differentiation. Biochim Biophys Acta 1996; 1302: 93-109, doi: 10.1016/0005-2760(96)00066-5.

3. Gervois P, Fruchart JC, Staels B. Inflammation, dyslipidaemia, diabetes and PPars: pharmacological interest of dual PPARalpha and PPARgamma agonists. Int J Clin Pract Supp/ 2004; 22-29, doi: 10.1111/j.1368-504X.2004.00376.x.

4. Girnun GD, Chen L, Silvaggi J, Drapkin R, Chirieac LR, Padera $\mathrm{RF}$, et al. Regression of drug-resistant lung cancer by the combination of rosiglitazone and carboplatin. Clin Cancer Res 2008; 14: 6478-6486, doi: 10.1158/1078-0432.CCR-08-1128.

5. Dai Y, Qiao L, Chan KW, Zou B, Ma J, Lan HY, et al. Loss of XIAP sensitizes rosiglitazone-induced growth inhibition of colon cancer in vivo. Int J Cancer 2008; 122: 2858-2863, doi: $10.1002 / \mathrm{ijc} .23443$.

6. Gaetano C, Colussi C, Capogrossi MC. PEDF, PPAR-gamma, p53: deadly circuits arise when worlds collide. Cardiovasc Res 2007; 76: 195-196, doi: 10.1016/j.cardiores.2007.08.011.

7. Koga H, Sakisaka S, Harada M, Takagi T, Hanada S, Taniguchi E, et al. Involvement of p21(WAF1/Cip1), p27(Kip1), and $\mathrm{p} 18(\mathrm{INK} 4 \mathrm{c})$ in troglitazone-induced cell-cycle arrest in human hepatoma cell lines. Hepatology 2001; 33: 1087-1097, doi: 10.1053/jhep.2001.24024. was strong even when p53 expression was markedly reduced by siRNA, suggesting that the effect of PPAR $\gamma$ on luciferase activity is likely due to direct interaction of PPAR $\gamma$ on the IGFBP promoter, rather than to indirect regulation by p53. We previously reported that the exogenous addition of IGFBP-3 inhibited the growth of cells not expressing IGFBP-3, causing them to undergo apoptosis (27). Our demonstration of induction of apoptosis by PPAR $\gamma$ in SNU668 cells (Figure 1B) is in accordance with that observation.

In summary, our data indicated that PPAR $\gamma$ can act as a transcription factor, and that one mechanism whereby it exerts an antitumor effect in gastric cancer cells is by increasing expression of the tumor suppressor gene IGFBP-3. There have been few studies of the interaction of PPAR $\gamma$ with IGFs (28), and there are no specific data on IGFBP-3. Additional data demonstrating a role for PPAR $\gamma$ in increasing the anticancer potential of IGFBP-3 may provide new approaches for treatment of gastric cancers.

\section{Acknowledgments}

The authors thank Dr. Zena K. Indik (Department of Medicine, University of Pennsylvania, Philadelphia, PA, USA) and Professor Kannan (Division of Biotechnology, Advanced Institute of Biosciences, Chonbuk National University, Jeonju, Korea) for their careful review of the manuscript and comments.
8. Xin X, Yang S, Kowalski J, Gerritsen ME. Peroxisome proliferator-activated receptor gamma ligands are potent inhibitors of angiogenesis in vitro and in vivo. J Biol Chem 1999; 274: 9116-9121, doi: 10.1074/jbc.274.13.9116.

9. Goetze S, Bungenstock A, Czupalla C, Eilers F, Stawowy P, Kintscher $U$, et al. Leptin induces endothelial cell migration through Akt, which is inhibited by PPARgamma-ligands. Hypertension 2002; 40: 748-754, doi: 10.1161/01.HYP.00000 35522.63647.D3.

10. Baxter RC, Martin JL. Binding proteins for the insulin-like growth factors: structure, regulation and function. Prog Growth Factor Res 1989; 1: 49-68, doi: 10.1016/0955-2235(89) 90041-0.

11. Kelley KM, Oh Y, Gargosky SE, Gucev Z, Matsumoto T, Hwa $V$, et al. Insulin-like growth factor-binding proteins (IGFBPs) and their regulatory dynamics. Int J Biochem Cell Biol 1996; 28: 619-637, doi: 10.1016/1357-2725(96)00005-2.

12. Colston KW, Perks CM, Xie SP, Holly JM. Growth inhibition of both MCF-7 and Hs578T human breast cancer cell lines by vitamin $\mathrm{D}$ analogues is associated with increased expression of insulin-like growth factor binding protein-3. J Mol Endocrinol 1998; 20: 157-162, doi: 10.1677/jme.0.0200157.

13. Rozen F, Zhang J, Pollak M. Antiproliferative action of tumor necrosis factor-alpha on MCF-7 breastcancer cells is associated with increased insulin-like growth factor binding protein-3 accumulation. Int J Oncol 1998; 13: 865-869.

14. Buckbinder L, Talbott R, Velasco-Miguel S, Takenaka I, Faha B, Seizinger BR, et al. Induction of the growth inhibitor IG 
F-binding protein 3 by p53. Nature 1995; 377: 646-649, doi: 10.1038/377646a0.

15. Kim MS, Kim SY, Arunachalam S, Hwang PH, Yi HK, Nam $S Y$, et al. c-myb stimulates cell growth by regulation of insulin-like growth factor (IGF) and IGF-binding protein-3 in K562 leukemia cells. Biochem Biophys Res Commun 2009; 385: 38-43, doi: 10.1016/j.bbrc.2009.05.018.

16. He TC, Zhou S, da Costa LT, Yu J, Kinzler KW, Vogelstein B. A simplified system for generating recombinant adenoviruses. Proc Natl Acad Sci U S A 1998; 95: 2509-2514, doi: 10.1073/pnas.95.5.2509.

17. Ahmadian M, Suh JM, Hah N, Liddle C, Atkins AR, Downes $\mathrm{M}$, et al. PPARgamma signaling and metabolism: the good, the bad and the future. Nat Med 2013; 19: 557-566, doi: 10.1038/nm.3159.

18. Walker GE, Wilson EM, Powell D, Oh Y. Butyrate, a histone deacetylase inhibitor, activates the human IGF binding protein-3 promoter in breast cancer cells: molecular mechanism involves an Sp1/Sp3 multiprotein complex. Endocrinology 2001; 142: 3817-3827, doi: 10.1210/endo.142.9.8380.

19. Lin J, Beerm DG. Molecular biology of upper gastrointestinal malignancies. Semin Oncol 2004; 31: 476-486, doi: 10.1053/ j.seminoncol.2004.04.019.

20. Yaacob NS, Darus HM, Norazmi MN. Modulation of cell growth and PPARgamma expression in human colorectal cancer cell lines by ciglitazone. Exp Toxicol Pathol 2008; 60: 505-512, doi: 10.1016/j.etp.2008.05.006.

21. Chen YX, Zhong XY, Qin YF, Bing W, He LZ. 15d-PGJ2 inhibits cell growth and induces apoptosis of MCG-803 human gastric cancer cell line. World J Gastroenterol 2003; 9: $2149-2153$

22. Ramachandran L, Manu KA, Shanmugam MK, Li F, Siveen KS, Vali S, et al. Isorhamnetin inhibits proliferation and invasion and induces apoptosis through the modulation of peroxisome proliferator-activated receptor gamma activation pathway in gastric cancer. J Biol Chem 2012; 287: 3802838040, doi: 10.1074/jbc.M112.388702.

23. Vara D, Morell C, Rodriguez-Henche N, Diaz-Laviada I. Involvement of PPARgamma in the antitumoral action of cannabinoids on hepatocellular carcinoma. Cell Death Dis 2013; 4: e618, doi: 10.1038/cddis.2013.141.

24. Collard TJ, Guy M, Butt AJ, Perks CM, Holly JM, Paraskeva $\mathrm{C}$, et al. Transcriptional upregulation of the insulin-like growth factor binding protein IGFBP-3 by sodium butyrate increases IGF-independent apoptosis in human colonic adenoma-derived epithelial cells. Carcinogenesis 2003; 24: 393-401, doi: 10.1093/carcin/24.3.393.

25. Bonofiglio D, Aquila S, Catalano S, Gabriele S, Belmonte M, Middea E, et al. Peroxisome proliferator-activated receptorgamma activates p53 gene promoter binding to the nuclear factor-kappaB sequence in human MCF7 breast cancer cells. Mol Endocrinol 2006; 20: 3083-3092, doi: 10.1210/ me.2006-0192.

26. Lee DY, Yi HK, Hwang PH, Oh Y. Enhanced expression of insulin-like growth factor binding protein-3 sensitizes the growth inhibitory effect of anticancer drugs in gastric cancer cells. Biochem Biophys Res Commun 2002; 294: 480-486, doi: 10.1016/S0006-291X(02)00491-6.

27. Lecka-Czernik B, Acckert-Bicknell C, Adamo ML, Marmolejos V, Churchill GA, Shockley KR, et al. Activation of peroxisome proliferator-activated receptor gamma (PPARgamma) by rosiglitazone suppresses components of the insulin-like growth factor regulatory system in vitro and in vivo. Endocrinology 2007; 148: 903-911, doi: 10.1210/ en.2006-1121.

28. Higashi $\mathrm{Y}$, Holder $\mathrm{K}$, Delafontaine $\mathrm{P}$. Thiazolidiones upregulate insulin-like growth factor-1 receptor via a peroxisome proliferator-activated receptor gamma independent pathway. J Biol Chem 2010; 285: 36361-36368, doi: 10.1074/ jbc.M110.137661. 